\title{
An Exploratory Research on Structure of Percieved Residential Environment Quality
}

\author{
Maria Khosravi ${ }^{1 . a}$, Sr Dr Norngainy Mohd Tawil ${ }^{2}$ Morteza Monshizadeh $^{3}$ \\ ${ }^{1}$ Ph.D. Student Universiti Kebangsaan Malaysia, Architecture Department \\ ${ }^{2}$ Deputy Director of CESMED Universiti Kebangsaan Malaysia \\ ${ }^{3}$ Ph.D. Student Universiti Kebangsaan Malaysia, Architecture Department
}

\begin{abstract}
Housing is a composite entity (in the sense of Gary Becker) that fulfils several human need. The main need that this commodity is to fulfil is dwelling, but from environmental satisfaction point of view, housing is more than a dwelling unit and its set of objective characteristics, since it also provides health services, security, privacy, neighborhood and social relations, status, community facilities and services, access to jobs and control over the environment. Thus, the principal way in which individual satisfaction with housing is measured through direct questions about their level of housing satisfaction. The purpose of this paper then is to contribute further research on the conceptualization of individual housing satisfaction as a particular domain of satisfaction with life as a whole, providing empirical evidence to disentangle the effects housing characteristics (hedonic), individual and household characteristics (predictive), as well as social interactions originated in one's residential neighborhood on this housing satisfaction domain. The main contributions of this paper in relation to previous work are the following. First, the simultaneous inclusion of the hedonic and predictive approach in our valuation (by comparing individuals satisfaction and individuals importance values), Second, we also investigate the relations between values in satisfaction and importance. This qualitative exploratory attempt has done by a data gathering through a close ended questionnaire that is made of focus group research.
\end{abstract}

\section{Introduction}

Housing is a composite entity (in the sense of Gary Becker) that fulfils several human need. The main need that this commodity is to fulfil is dwelling, but from environmental satisfaction point of view, housing is more than a dwelling unit and its set of objective characteristics, since it also provides health services, security, privacy, neighborhood and social relations, status, community facilities and services, access to jobs and control over the environment. Thus, the principal way in which individual satisfaction with housing is measured through direct questions about their level of housing satisfaction. The purpose of this paper then is to contribute further research on the conceptualization of individual housing satisfaction as a particular domain of satisfaction with life as a whole, providing empirical evidence to disentangle the effects housing characteristics (hedonic), individual and household characteristics (predictive), as well as social interactions originated in one's residential neighborhood on this housing satisfaction domain. The main contributions of this paper in relation to previous work are the following. First, the simultaneous inclusion of the hedonic and predictive

\footnotetext{
${ }^{a}$ Maria Khosravi: Mariakh57@hotmail.com
}

approach in our valuation (by comparing individuals satisfaction and individuals importance values), Second, we also investigate the relations between values in satisfaction and importance. This qualitative exploratory attempt has done by a data gathering through a close ended questionnaire that is made of focus group research.

\section{Residential quality residential environment preference}

Housing is one of the basic human needs for well-being, the securing of which is fundamental to our quality of life (Y. Sun, 2005).Davies (1938) use "home surroundings" and "neighborhood qualities" to assess good housing standards. Physical health and mental well-being and security are included in the evaluation criteria. Yard for children's play, location, harmony between house plan and the surroundings, adequate landscaping, and convenience are included in problems related to home environment.

Baer (1986) and Sloane (2006) adopt an expanded checklist of APHA on housing and planning studies, Baer (1986) provides a historical review of the evolution of local and regional housing studies and their political uses. 
The next step concluded in the research is to create a supply side counterpart to housing need analysis to suggest how the dynamics of the existing stock can be better used to meet some of the fair share need. Sloane (2006) addresses whether the concept of sprawl is rich enough to foster sustainable, long-term connections between the fields of planning and public health. It finds that sprawl is not just about suburbs; highly segregated communities with poor nutritional and recreational environments aggravate high rates of obesity. Obesity is not the only adverse outcome of sprawl, and physical activity is not the only contributor to overweight. It concludes that planners should resist environmental determinism and remain open to the influence of social, political, cultural, and economic influences, as well as those of the built environment, on human behavior.

Brown and Moore (1970) provide a framework for understanding housing choice decision making. They use the concept of 'place utility' to measure the balance of residential satisfaction and dissatisfaction. The balance creates a central notion for interpreting residential mobility (Z. Li \& Wu, 2006). Number of factors influencing the determining selection of the new residence are identified: accessibility, physical characteristics of the neighborhood, services and facilities, social environment, individual site and dwelling characteristics (Brown \& Moore, 1970). Rouwendal and Meijer (2001) state that, among other things, the household preferences (and therefore also their willingness - to - pay) for housing attributes that are especially available outside large cities are substantial enough to make acceptance of long commutes attractive to many employees (Rouwendal \& Meijer, 2001).

Harris et al (1968) scale the residence site choice by measuring the amenity and travel savings components of land value (Harris, Tolley, \& Harrell, 1968). The measurement of amenity and travel savings components of land value reveals that both are major components of land value. Amenity is one of the main commodities people wish to acquire when their incomes rise. Kain and Quigley point out there are other factors impacting housing quality, such as air pollution, accessibility to downtown and school quality (Kain \& Quigley, 1970).

Ball and Srinivasan (1994) present a model of housing selection process using the analytic hierarchy process (AHP), which allows the buyer to consistently evaluate property attributes. Schniederjans et al., (1995) also present a Goal Programming model that utilizes the AHP to evaluate property attributes and make an optimal house selection decision. Table 1 presents the research factors they used in housing selection process.

Karsten(2007) indicates that housing quality is composed of two major ingredients: the site (accommodation of daily life) and the situation (location) of the neighborhood. The environment of housing includes facilities, infrastructures and services that are available within and beyond the neighborhood, amenities that are proximate in and near the neighborhood, and the social capital in neighborhood.
Table 1. Research factors in Housing Selection Source: Ball \& Srinivasan (1994).

\begin{tabular}{ll}
\hline Categories & Factors \\
\hline Proximate & Commute to Work, Member A \\
& Commute to Work, Member B \\
& Proximity to Other Locations \\
& Schools \\
& Shopping \\
& Church and other regularly frequented places \\
\hline Community & Quality of Schools \\
& Government Services/Taxes \\
& Social Considerations \\
& Entertainment \\
\hline Neighborhood & Aesthetics \\
& Quality of Infrastructure \\
& Landscaping, autos, etc. \\
& Infrastructure \\
\hline Lot \\
Utility of usable space \\
Landscape, lawn, foliage, privacy, etc. \\
Walkway, driveway, fence, outbuilding, etc. \\
Building - Exterior \\
Condition of walls \\
Architectural design and garage \\
Building - Interior \\
Rooms \\
Systems \\
\hline
\end{tabular}

\section{Residential environment in concept}

Residential environment is a large topic to review. To study Residential environment, researchers have conducted research on house quality (Association \& Housing, 1945; Fiadzo, et al., 2001; Rindfuss, et al., 2007), residential satisfaction (Adriaanse, 2007; Fang, 2006; Kellekci \& Berkoz, 2006), housing environmental quality (Ha \& Weber, 1994), attractiveness of residence (Kauko, 2006; Linneman, 1981), neighborhood attachment(Hays \& Alexandra, 2007; Karien, 2007; L. H. Li, 2008b), and social capital (Kevin, 2003; Kleinhans, et al., 2007; Middleton, et al., 2005).

\section{Evaluation of residential environment}

Lansing and Marans (1969) develop a method using an attitude survey to evaluate neighborhood quality throughout a metropolitan area. This method illustrates how a planner's judgment may be congruous or incongruous with that of the residential community and suggests ways in which analytical relationships between planners' and citizens' values may be used in developing a model for determining residential satisfaction. Baba and Austin (1989) shed light on the neighborhood safety when measuring the neighborhood environmental quality. They suggest that improving the quality of neighborhood environmental characteristics will increase residents' concerns with safety.

Ge and Hokao (2004) use hierarchical multi-attributes evaluation model to access the residential environment. Questionnaire surveys and subjective evaluations on residential environment are performed in order to grasp the main factors of residential environment of small local 
cities. They establish an evaluation index system and analyze the regional residential environment characteristics and personal residential preference types. The environmental criteria include convenience, amenities, health, safety, and community. Some of the criteria are adopted in this study.

To assess the determinants of user satisfaction in housing and environmental quality in order to provide maximum level of user satisfaction, Berkoz et al. (2009) survey to measure the user satisfaction in housing and environmental quality, and to determine the factors increasing the level of satisfaction. Relative factors are presented on the questionnaires: the characteristics of household members (the size of the household, gender, age, education, the number of people working, profession, income group, ownership of durable consumer goods, and ownership of vehicles), features related to the housing (when the household moved into the housing, ownership of the housing, housing type, size of the housing, the number of inhabitants, the previous neighborhood, the previous housing type), accessibility (accessibility to work, to the center where the daily needs are met, shopping center, city center, school, sports facilities, walking areas, refreshment areas, car parking areas, health institutions, education institutions, entertainment areas, recreational areas, public transport stops, and to close relatives and friends), characteristics of the housing environment (lighting, maintenance of open areas, maintenance of green areas, traffic density, user density, building density, housing environment facilities), security (fire, natural disasters, traffic accidents, robbery, murder), neighbor relationships (neighbors of similar social background, acquaintance with people nearby, privacy, charity among neighbors), and the appearance of the housing environment (monotony, being interesting, reflecting the social status, economic value)(Berkoz, et al., 2009). Figure 1 presents the conceptual model of their study.

Figure 1. Conceptual model developed for user satisfaction in housing and environmental quality. Source: (Berkoz, et al., 2009).

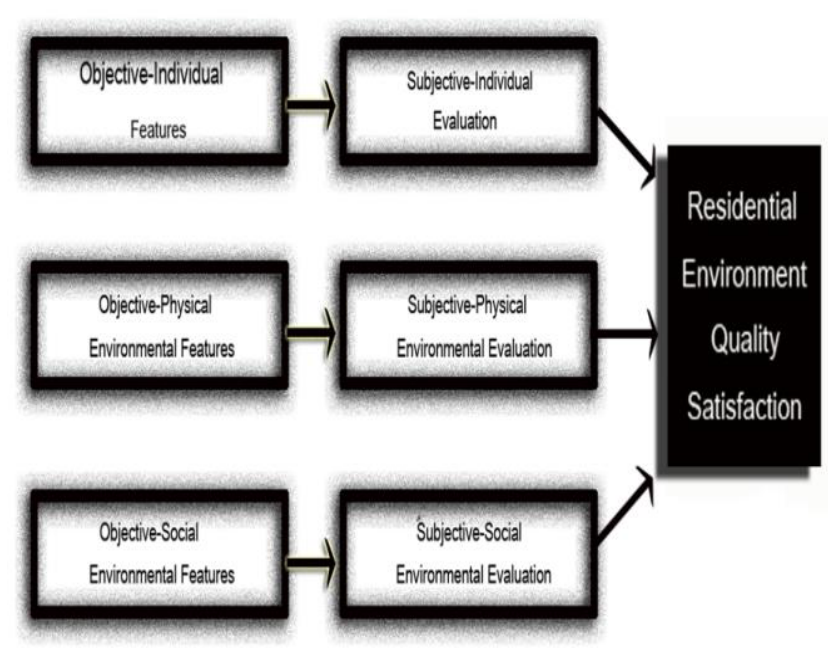

\section{Important residential environment factors}

\subsection{Mobility}

Accessibility of housing is considered very important to the quality of Residential Environment. Plenty of studies about public and private traffic network and commute can be found in Anderson, Kanaroglou, \& Miller, 1996; Cervero, 1996a; Cervero \& Wu, 1998; Levine, 1998; Peng, 1997; Wachs, Taylor, Levine, \& Ong, 1993 (Cervero, 1996a; Cervero \& Wu, 1998; Levine, 1998; Peng, 1997; Wachs, Taylor, Levine, \& Ong, 1993). Kellekci and Berkoz (2006) conduct accessibility in their research on housing quality and environmental satisfaction. Accessibility in their thesis refers to work, to the center where the daily needs are met, shopping center, city center, school, sports facilities, walking areas, refreshment areas, car parking areas, health institutions, education institutions, entertainment areas, recreational areas, public transport stops, and to close relatives and friends. Public traffic network, Private traffic network, Proximity to urban center, and Proximity to workplace are mentioned in researchers study as main factors of mobility (Mills, 1994, Linneman, 1981, Bontje 2004).

\subsection{Community facilities}

To measure the satisfaction of housing and its environment, Kellekci and Berkoz (2006) adopt characteristics of the Residential Environment as one of the indicators, which includes lighting, maintenance of open areas, traffic density, user density, building density, housing environment facilities Education Facility (EDF), adopt good place to raise children and schools, Medical and Health Facility (MHF), Retail Service (RES), shopping and sport facilities..

\subsection{Community social capital}

The important influence of social capital to housing environment and neighborhood attachment are studied in a great number of literatures. Middleton et al (2005) find that social capital is seen as the foundation on which social stability and community's ability to help itself is built; and its absence is thought to be a key factor in neighborhood decline. Temkin and Rohe (1998) find that neighborhood activities, such as borrowing small items and visiting, would occur in environments in which residents trusted one another and might be thought of as a proxy for the level of trust among neighborhood residents. Even more, housing environment in social aspect affects the social life of residents. A key issue for the discussion of social capital 
is the extent to which residents in any neighborhood perceive themselves to be part of the same community. Neighborhoods are important sources of "social identity" (Forrset and Kearns, 2001).

\section{Methodology}

The main objective of this study is to understand the demand pattern and preferences on structuring the perceived residential environment quality by consumers the international Iranian Postgraduate student in KL, Malaysia and offer more information for urban planners and housing developers about housing environmental demand from social and cultural perspective. In order to achieve this objective, a hierarchy of housing environment quality attributes is developed. This research was undertaken in the Klang Valley Condominiums in Malaysia. Data collection was conducted through a field study using a questionnaire filled in by a sample of 30 students for pilot study and 300 students for main designed questionnaire. Data analysis was also conducted using SPSS software. Mixed method research encourages researchers to combine inductive and deductive thinking to answer questions that cannot be answered by qualitative or quantitative approaches alone (Creswell and Plano Clark, 2007). The combination of methods can assist in tackling highly complex problems involving several layers of understanding (Hesse-Biber and Leavy, 2011). However, mixed method research is not easy as it requires the researcher to be proficient in both forms of inquiry and it takes time to collect the required data (Creswell and Plano Clark, 2007). Reasons why researchers might want to use a mixed method approach include (i) using different theoretical approaches on the same research question to enhance credibility (triangulation), (ii) to give a fuller understanding of a research question or to clarify a result (complementarity), (iii) to use result from one method to develop or inform another method (development), (iv) where a studies results raise questions or contain contradictions which require clarification (initiation) or (v) where a researcher decides to expand into a whole new investigation (expansion) (Hesse-Biber and Leavy, 2011; Greene et al., 1989)(figure2).
Figure 2. Mixed method used in research methodology.
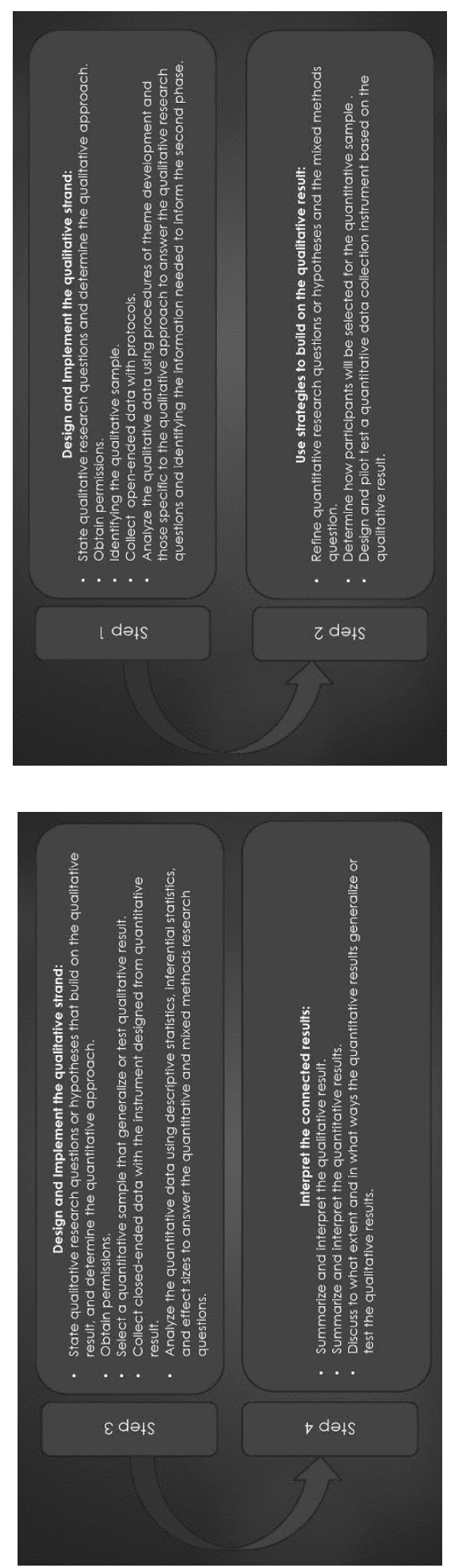


\section{Theoretical framework}

This model was developed from previous works on housing environments and location preference (Bender et al., 1997, 2000; Kauko, 2006, 2007; Yam et al., 2008; Fan, 2010;Mohit \& Nazyddah, 2011).Basically the hole study focuses on three major physical scale (Housing characteristics, Neighborhood characteristics, and Regional characteristics) to model the frame (figure 3,4).

Figure 3. Modified model of housing environment quality. Source: (Bender, et al., 2000).

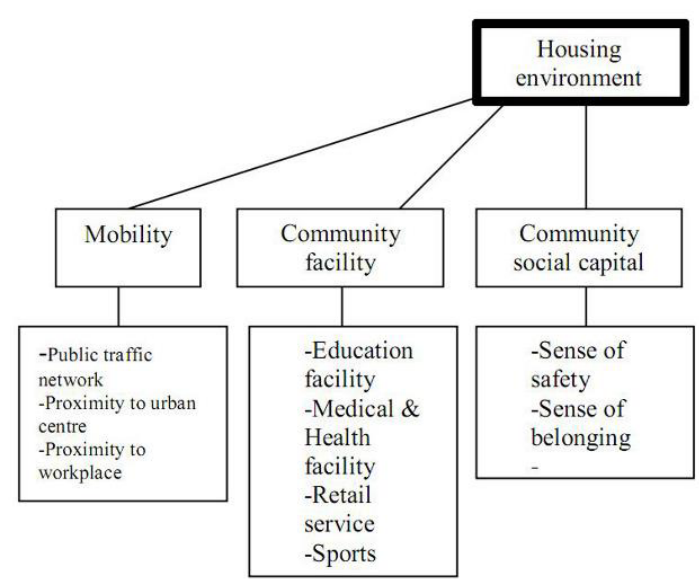

Figure 4. Modified Framework Housing environment Quality of for the study.

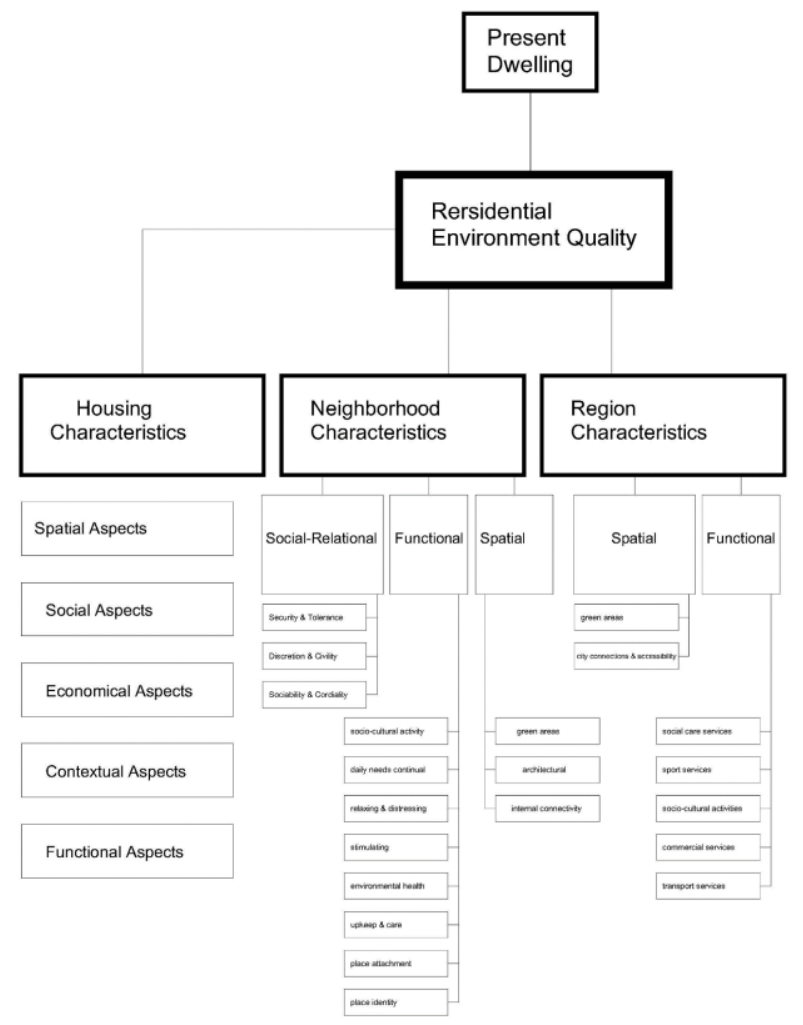

\section{Result and analysis}

Gathered data were analyzed using the statistical package for Social Science (SPSS) and the results of analyzing data are presented. First of all an introductorily examination of the data is described which includes the procedure involved in data cleaning and screening, descriptive statistics and correlation analysis. Results of hypotheses tests according to objectives of study entitled "An

Exploratory Assessment on Iranian International Student's Accommodation Satisfaction" are discussed in their order by using Repeated Measures, ANOVA, T-Test, and Pearson's Correlation test. The analysis included:

- Descriptive analysis of variables

- Inferential analysis

Figure 5. Modified model of accommodation satisfaction level and satisfaction measurements.

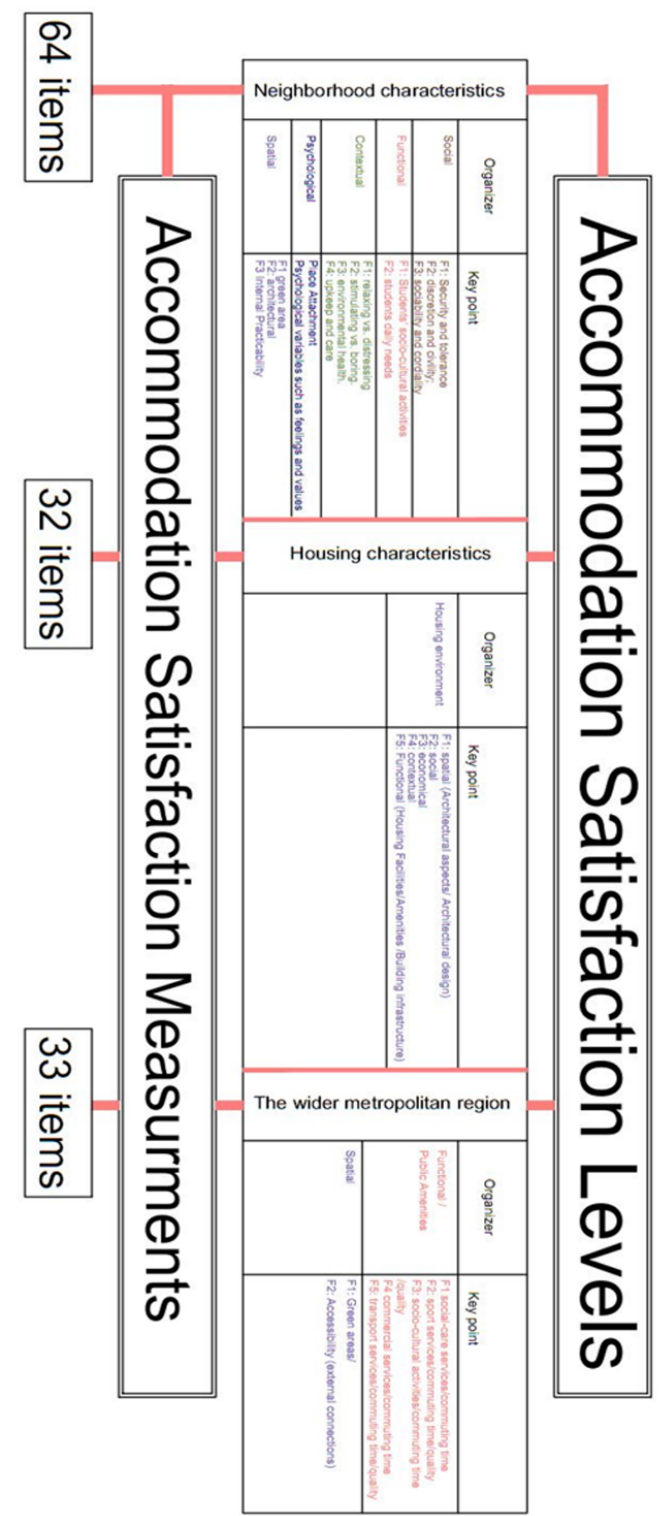


Data gathered in two main descriptive satisfaction level and importance level of users and as depicted in figure 5 categorized as 64 item for neighborhood characteristics, 32 item on housing characteristics, and 33 item on wider metropolitan region. The neighborhood characteristics are examined as social, functional, contextual, psychological, and spatial organizers, housing characteristics as housing environment organizers and regional characteristics as functional and spatial features. The Exploratory Assessment on Iranian International Student's Accommodation Satisfaction showed the modified model of residential can be used as a structure of perceived residential environment quality on three major scale of housing, neighborhood, and region.

\section{References}

1. Adriaanse, C. C. M. (2007). Measuring residential satisfaction: a residential environmental satisfaction scale (RESS). Journal of Housing and the Built Environment, 22(3), 287.

2. Altman, I., \& Werner, C. M. (1985). Home environments (Vol. 8). New York: Plenum Press.

3. Altman, I., \& Wohlwill, J. F. (1976). Human behavior and environment: advances in theory and research. New York: Plenum Press.

4. Ball, J. n., \& Srinivasan, V. C. (1994). Using the Analytic Hierarchy Process in house selection. The Journal of Real Estate Finance and Economics, 9(1), 69-85.

5. Baer, W. C. (1986). The Evolution of Local and Regional Housing Studies. Journal of the American Planning Association, 52(2), 172 184.

6. Bender, A., Din, A., Favarger, P., Hoesli, M., \& Laakso, J. (1997). An Analysis of Perceptions Concerning the Environmental Quality of Housing in Geneva. Urban Studies, 34(3), 503513.

7. Berkoz, L., Turk, S., \& Kellekci, M. (2009). Environmental Quality and User Satisfaction in Mass Housing Areas: The Case of Istanbul. European Planning Studies, 17(1), 161.

8. Bontje, M. (2004). From suburbia to postsuburbia in the Netherlands: Potentials and threats for sustainable regional development. Journal of Housing and the Built Environment, 19(1), 25.

9. Brown, L. A., \& Moore, E. G. (1970). The IntraUrban Migration Process: A Perspective. Geografiska Annaler, 52(1), 13.

10. Cervero, R. (1996b). Jobs-housing balance revisited. American Planning Association. Journal of the American Planning Association, 62(4), 492.

11. Chapple, K. (2006). Overcoming Mismatch: Beyond Dispersal, Mobility, and Development Strategies. American Planning Association.
Journal of the American Planning Association, 72(3), 322.

12. Davies, J. E. (1938). Fundamentals of housing study: a determination of factors basic to an understanding of American housing problems. New York: AMS Press.

13. Fang, Y. (2006). Residential Satisfaction, Moving Intention and Moving Behaviours: A Study of Redeveloped Neighbourhoods in InnerCity Beijing. Housing Studies, 21(5), 671.

14. Fiadzo, E. D., Houston, J. E., \& Godwin, D. D. (2001). Estimating housing quality for poverty and development policy analysis: CWIQ in Ghana. Social Indicators Research, 53(2), 137.

15. Ge, J., \& Hokao, K. (2004). Residential environment index system and evaluation model established by subjective and objective methods. Journal of Zhejiang University SCIENCE, $5(9), 7$.

16. Gober, P., McHugh, K. E., \& Leclerc, D. (1993). Job-rich but housing poor: The dilemma of a Western amenity town. Professional Geographer, 45(1), 12.

17. Ha, M., \& Weber, M. J. (1994). Residential quality and satisfaction: Toward developing residential quality indexes. Home Economics Research Journal, 22(3), 296.

18. Harris, R. N. S., Tolley, G. S., \& Harrell, C. (1968). The Residence Site Choice. Review of Economics \& Statistics, 50(2), 241.

19. Hays, R. A., \& Alexandra, M. K. (2007). Neighborhood attachment, social capital building, and political participation: A case study of low-and moderate-income residents of Waterloo, Iowa. Journal of Urban Affairs, 29(2), 181.

20. Kain, J. F., \& Quigley, J. M. (1970). Measuring the Value of Housing Quality. Journal of the American Statistical Association, 65(330), 532548.

21. Karien, D. (2007). Social Capital, Neighbourhood Attachment and Participation in Distressed Urban Areas. A Case Study in The Hague and Utrecht, the Netherlands. Housing Studies, 22(3), 355.

22. Karsten, L. (2007). Housing as a Way of Life: Towards an Understanding of Middle-Class Families' Preference for an Urban Residential Location. Housing Studies, 22, 83.

23. Kauko, T. (2006). What makes a location attractive for the housing consumer? Preliminary findings from metropolitan Helsinki and Randstad Holland using the analytical hierarchy process. Journal of Housing and the Built Environment, 21(2), 159.

24. Kellekci, O. L., \& Berkoz, L. (2006). Mass Housing: User Satisfaction in Housing and its Environment in Istanbul, Turkey. European Journal of Housing Policy, 6(1), 77-99

25. Kleinhans, R., Priemus, H., \& Engbersen, G. (2007). Understanding Social Capital in Recently Restructured Urban Neighbourhoods: 
Two Case Studies in Rotterdam. Urban Studies, 44(5/6), 1069.

26. Lansing, J. B., \& Marans, R. W. (1969). Evaluation of Neighborhood Quality. Journal of the American Planning Association, 35(3), 5.

27. Levine, J. (1998). Rethinking accessibility and jobs-housing balance. American Planning Association. Journal of the American Planning Association, 64(2), 133.

28. Leyden, K. M. (2003). Social capital and the built environment: The importance of walkable neighborhoods. American Journal of Public Health, 93(9), 1546.

29. Li, L. H. (2008a). The physical environment and a "sense of neighborhood" in residential communities in Hong Kong. Property Management, 26, 7.

30. Linneman, P. (1981). The demand for residence site characteristics. Journal of Urban Economics, 9(2), 129-148.

31. Li, Z., \& Wu, F. (2006). Socio-spatial Differentiation and Residential Inequalities in Shanghai: A Case Study of Three Neighbourhoods. Housing Studies, 21(5), 695.

32. Ma, K.-R., \& Banister, D. (2006). Extended Excess Commuting: A Measure of the JobsHousing Imbalance in Seoul. Urban Studies, 43(11), 2099.

33. Middleton, A., Murie, A., \& Groves, R. (2005). Social Capital and Neighborhoods that Work. Urban Studies, 42(10), 1711.

34. Ottensmann, J. R. (1977). Urban Sprawl, Land Values and the Density of Development. Land Economics, 53(4), 389.

35. Peck, C., \& Stewart, K. (1985). Satisfaction with Housing and Quality of Life. Home Economics Research Journal, 13(4), 10.

36. Peng, Z.-R. (1997). The jobs-housing balance and urban commuting. Urban Studies, 34(8), 1215.

37. Ricardo, A., Frank, D., Rebecca, P., Hollie, T., $\&$ et al. (2006). Perceptions of social capital and the built environment and mental health. Social Science \& Medicine, 62(12), 3072.

38. Rindfuss, R. R., Piotrowski, M., Thongthai, V., \& Prasartkul, P. (2007). Measuring housing quality in the absence of a monetized real estate market. Population Studies, 61(1), 35.

39. Rouwendal, J., \& Meijer, E. (2001). Preferences for housing, jobs, and commuting: A mixed logit analysis. Journal of Regional Science, 41(3), 475.

40. Sarzynski, A., Wolman, H. L., Galster, G., \& Hanson, R. (2006). Testing the Conventional Wisdom about Land Use and Traffic Congestion: The More We Sprawl, the Less We Move? Urban Studies, 43(3), 26.

41. Schniederjans, M. J., Hoffman, J. J., \& Sirmans, G. S. (1995). Using Goal Programming and the Analytic Hierarchy Process in House Selection. The Journal of Real Estate Finance and Economics, 11(2), 167-176.
42. Sloane, D. C. (2006). Longer View: From Congestion to Sprawl: Planning and Health in Historical Context. Journal of the American Planning Association, 72(1), 10 - 18.

43. Sun, Y. (2005). Development of neighbourhood quality of life indicators. Temkin, K., \& Rohe, W. M. (1998). Social Capital and Neighborhood Stability: An Empirical Investigation. Housing Policy Debate, 9(1), 28.

44. Temkin, K., \& Rohe, W. M. (1998). Social Capital and Neighborhood Stability: An Empirical Investigation. Housing Policy Debate, 9(1), 28 